\title{
RESPOSTA DE HÍBRIDOS DE MILHO IRRIGADO À DENSIDADE DE PLANTAS EM TRÊS ÉPOCAS DE SEMEADURA ${ }^{1}$
}

\author{
PAULO REGIS FERREIRA DA SILVA², GILBER ARGENTA ${ }^{3}$ e FABIANA REZERA ${ }^{4}$
}

\begin{abstract}
RESUMO - A determinação da densidade ótima de semeadura do milho, além de ser influenciada pelas características dos híbridos, pelo nível de fertilidade do solo e pela disponibilidade hídrica, pode também variar de acordo com a época da semeadura, uma vez que ela afeta o crescimento e desenvolvimento da planta. Com o objetivo de determinar a densidade ótima de planta em híbridos de milho com elevado potencial de rendimento de grãos, em três épocas de semeadura, com relação a rendimento de grãos, componentes do rendimento e outras características agronômicas, foram feitos quatro experimentos na região fisiográfica da Depressão Central do Rio Grande do Sul, município de Eldorado do Sul, com suplementação hídrica por aspersão. Os tratamentos constaram de quatro híbridos (Pioneer 3063, Pioneer 3207, XL 212 e Cargill 901), quatro densidades de plantas (50, 70, 90 e $110.000 \mathrm{pl} / \mathrm{ha}$ ) e de três épocas de semeadura (agosto, outubro e dezembro). Não há resposta à densidade de plantas dos híbridos de milho testados nas épocas de semeadura de agosto e dezembro. $\mathrm{O}$ aumento na densidade de plantas somente foi vantajosa na semeadura de outubro, quando se obtiveram maiores rendimentos de grãos na densidade de $70.000 \mathrm{pl} / \mathrm{ha}$, independentemente do híbrido avaliado, nas duas estações de crescimento.
\end{abstract}

Termos para indexação: Zea mays, rendimento de grãos, componentes do rendimento.

\section{RESPONSE OF IRRIGATED CORN HYBRIDS TO PLANT DENSITY IN THREE SOWING DATES}

\begin{abstract}
Plant density response of corn besides influenced by hybrids traits, soil fertility level and water availability, could also vary with sowing date, since it affects plant growth and development. With the objective of determining the most adequate plant density of corn hybrids with high potential grain yields, in three sowing dates, in relation to grain yields, yield components and other agronomic traits, four experiments were conducted in the state of Rio Grande do Sul, Brazil, with complementary irrigation. The treatments were composed by four hybrids (Pioneer 3063, Pioneer 3207, XL 212 and Cargill 901), four plant densities (50, 70, 90 and 110,000 pl/ha) and three sowing dates (August, October and December). There was no response to plant density of corn hybrids tested at sowing dates of August and December. The increase in plant density was beneficial only in the sowing date of October, when the highest grain yield with $70,000 \mathrm{pl} /$ ha was obtained in two growing seasons, out of regard to the hybrids tested.
\end{abstract}

Index terms: Zea mays, grain yield, yield components.

\footnotetext{
${ }^{1}$ Aceito para publicação em 4 de agosto de 1998.

Trabalho parcialmente financiado pelo CNPq.

${ }^{2}$ Eng. Agr., Ph.D., Prof. Adjunto, Dep. de Plantas de Lavoura, Faculdade de Agronomia, Universidade Federal do Rio Grande do Sul (UFRGS), Av. Bento Gonçalves, 7712, Caixa Postal 776, CEP 91540-000 Porto Alegre, RS. Bolsista do CNPq. E-mail: plantas@vortex.ufrgs.br

${ }^{3}$ Eng. Agr., Estudante do Curso de Pós-Graduação em Fitotecnia, Faculdade de Agronomia, UFRGS. Bolsista da CAPES.

${ }^{4}$ Acadêmica do Curso de Graduação em Agronomia, UFRGS. Bolsista do CNPq.
}

\section{INTRODUÇÃO}

O aumento da densidade de plantas até determinado limite é uma técnica usada com a finalidade de elevar o rendimento de grãos da cultura do milho. Porém, o número ideal de plantas por hectare é variável, uma vez que a planta de milho altera o rendimento de grãos de acordo com o grau de competição intra-específica proporcionado pelas diferentes densidades de plantas. A capacidade de resposta à 
densidade de plantas depende das características do genótipo, da quantidade da radiação solar e da disponibilidade de água e de nutrientes (Peixoto, 1996).

Vários pesquisadores consideraram o próprio genótipo como principal determinante para o adequado dimensionamento da densidade de plantas (Colville \& McGill, 1964; Rutger \& Crowder, 1967; Silva, 1972; Souza, 1976). Esses trabalhos evidenciam uma associação direta entre ciclo e capacidade de resposta dos genótipos. Os genótipos de milho de ciclo precoce alcançam os máximos rendimentos de grãos em densidades mais elevadas do que os de ciclo normal. Esta resposta diferenciada é atribuída ao maior aumento da duração do subperíodo do pendoamento ao espigamento nos genótipos de ciclo normal e no percentual de plantas estéreis.

Além do aumento de plantas estéreis, as reduções do rendimento de grãos com a elevação da densidade de plantas são atribuídas ao decréscimo do número de grãos por espiga (Tetio-Kagho \& Gardner, 1988) e ao menor enchimento de grãos (Hashemi \& Herbert, 1992).

As características agronômicas introduzidas nos genótipos de milho desenvolvidos mais recentemente, como menor esterilidade de plantas, maior sincronismo entre pendoamento e espigamento, menor estatura da planta e altura de inserção da espiga, plantas com folhas de angulação mais ereta e elevado potencial produtivo determinam a necessidade de reavaliar as recomendações de práticas de manejo adotadas na cultura do milho.

Além dos genótipos, a radiação solar é outro fator que tem sido objeto de pesquisas para determinar a densidade ótima para a obtenção do máximo rendimento de grãos de milho. Neste sentido, trabalhos experimentais demonstram redução do rendimento de grãos de milho sob condições de sombreamento e aumento sob condições em que há enriquecimento de luz (Hashemi \& Herbert, 1992; Girardin \& Tollenaar, 1994). Alterações na quantidade de radiação solar disponível à planta ocorrem com a semeadura em diferentes épocas dentro da estação de crescimento, da redução e suplementação artificial de radiação ou através da variação da competição por luz obtida pela modificação da densidade de plantas (Noldin, 1985).
A época de semeadura é outro fator que pode influenciar a escolha de densidade ótima, por modificar o crescimento e o desenvolvimento da planta de milho. Nas semeaduras em épocas não preferenciais, há redução na estatura e na área foliar das plantas de milho, determinando menor eficiência na utilização da radiação solar. Assim, o aumento na densidade das plantas pode ser uma estratégia a ser adotada para compensar tais reduções, pelo aumento da capacidade fotossintética da comunidade de plantas.

O objetivo deste trabalho foi determinar a densidade ótima de plantas para híbridos de milho, em três épocas de semeadura.

\section{MATERIAL E MÉTODOS}

Três experimentos foram instalados no campo, no ano agrícola 1995/96, e um no ano agrícola 1996/97, na Estação Experimental Agronômica (EEA) da Universidade Federal do Rio Grande do Sul (UFRGS), em Eldorado do Sul, RS, com suplementação hídrica. O solo utilizado é classificado como Podzólico Vermelho-Escuro distrófico (Paleudult), e pertence à unidade de mapeamento São Jerônimo. O clima da região é classificado, segundo Köppen, como subtropical úmido, situado na transição entre os tipos fundamentais $\mathrm{cfa}_{1}$ (isoterma anual inferior a $18^{\circ} \mathrm{C}$ ) e $\mathrm{cfa}_{2}$ (isoterma anual superior a $18^{\circ} \mathrm{C}$ ) (Moreno, 1961).

Em 1995/96, três híbridos de milho (Pioneer 3063, Pioneer 3207 e Cargill 901) foram semeados em três densidades de plantas $(50.000,70.000$ e $90.000 \mathrm{pl} / \mathrm{ha})$ e em três épocas de semeadura $(21 / 08 / 95,10 / 10 / 95$ e 12/12/95). Cada época de semeadura foi considerada um experimento, sendo denominados Experimentos I, II e III, respectivamente. Em 1996/97, quatro híbridos de milho (Pioneer 3063, Pioneer 3207, Cargill 901 e XL 212) foram semeados em quatro densidades de plantas $(50.000$, $70.000,90.000$ e $110.000 \mathrm{pl} / \mathrm{ha}$ ) na época de semeadura de 07/10/96, correspondendo ao Experimento IV.

Antecedendo à cultura do milho nos dois anos agrícolas, foi semeada aveia-preta. Esta foi dessecada quando $50 \%$ das plantas estavam em floração, utilizando-se o herbicida glyfosato (540 g i.a./ha) em um volume de aplicação de 150 litros/ha de calda.

Nos Experimentos I, II e III, a adubação foi realizada por ocasião da semeadura, utilizando-se $30 \mathrm{~kg} / \mathrm{ha}$ de $\mathrm{N}$, $150 \mathrm{~kg} / \mathrm{ha}$ de $\mathrm{P}_{2} \mathrm{O}_{5}$ e $150 \mathrm{~kg} / \mathrm{ha}$ de $\mathrm{K}_{2} \mathrm{O}$. Em cobertura, foram aplicados $150 \mathrm{~kg} / \mathrm{ha}$ de $\mathrm{N}$, em duas épocas, sendo a primeira no estádio de 6-7 folhas, e a segunda, no estádio 
de 8-9 folhas do milho completamente desenvolvidas. No Experimento IV, foram aplicados na semeadura $30 \mathrm{~kg} / \mathrm{ha}$ de $\mathrm{N}, 120 \mathrm{~kg} / \mathrm{ha}$ de $\mathrm{P}_{2} \mathrm{O}_{5}$ e $100 \mathrm{~kg} / \mathrm{ha}$ de $\mathrm{K}_{2} \mathrm{O}$. Em cobertura, foram aplicados $130 \mathrm{~kg} / \mathrm{ha}$ de $\mathrm{N}$, em duas épocas, sendo a primeira no estádio de 5-6 folhas, e a segunda, no estádio de 7-8 folhas do milho, completamente desenvolvidas.

Nos quatro experimentos, a semeadura foi efetuada manualmente, com a utilização de saraquá, colocando-se três sementes por cova. Vinte dias após a emergência das plântulas, foi realizado desbaste, deixando-se uma planta por cova. O espaçamento entre linhas foi de $0,7 \mathrm{~m}$. Cada subparcela foi composta por cinco linhas de seis metros de comprimento. Foram consideradas como bordaduras as linhas de número 1 e 5 e os primeiros $5 \mathrm{~cm}$ de cada extremidade da subparcela. Para a determinação do rendimento de grãos e seus componentes, a área útil foi de $10,5 \mathrm{~m}^{2}$. Plantas daninhas e pragas foram controladas de modo a não interferirem no rendimento de grãos.

A necessidade de irrigação foi estipulada pela instalação de seis tensiômetros nas áreas experimentais, sendo três na profundidade de $25 \mathrm{~cm}$, e três na profundidade de $50 \mathrm{~cm}$. A irrigação foi realizada quando o potencial de água no solo foi inferior a $-0,04 \mathrm{Mpa}$. O sistema de irrigação utilizado foi o de aspersão, na vazão de $10 \mathrm{~mm} / \mathrm{hora}$.

As determinações efetuadas no ano agrícola 1995/96 constaram de: rendimento de grãos, número de espigas por planta, número de grãos por espiga, peso de mil grãos, porcentagem de plantas estéreis, índice de colheita, altura das plantas e de inserção da espiga. No ano agrícola 1996/97, além dessas determinações, foram avaliadas a área foliar e o índice de área foliar. O índice de colheita não foi determinado nesse ano.

O rendimento de grãos foi obtido pela extrapolação da produção obtida na área útil das subparcelas para um hectare, considerando-se a umidade-padrão de $13 \%$ (base úmida). O número de espigas por planta foi determinado pela razão entre o número de plantas e o número de espigas colhidas na área útil. O peso de mil grãos foi obtido pela contagem manual e pela posterior pesagem de 400 grãos. Este valor foi corrigido para umidade de 13\%, e por regra de três simples obteve-se o peso de mil grãos. O número médio de grãos por espiga foi determinado pela relação entre o peso de grãos na área útil da subparcela, multiplicado por mil e dividido pelo peso de mil grãos mais o número de espigas colhidas na área útil.

A porcentagem de plantas estéreis foi determinada dividindo-se o número de plantas estéreis pelo número de plantas totais da área útil. Os dados de percentagem de plantas estéreis foram transformados por raiz quadrada, objetivando a homogeneidade de variância. $\mathrm{O}$ índice de colheita foi calculado pela divisão do peso de grãos pelo peso total da parte aérea da planta (grãos+massa seca).
A altura de planta e de inserção de espiga foram determinadas considerando-se, respectivamente, a distância do colo da planta ao ápice do pendão e a distância do colo da planta até o ponto de inserção do colmo da primeira espiga formada.

A área foliar foi obtida pelo método proposto por Francis et al. (1969). Determinou-se o índice de área foliar pela razão entre a área foliar de uma planta e a área de solo por ela ocupada.

Em todos os experimentos, o delineamento experimental utilizado foi o de blocos completamente casualizados, dispostos em parcelas subdivididas, com quatro repetições. $\mathrm{O}$ fator híbridos foi locado na parcela principal e o fator densidade de plantas nas subparcelas.

Os resultados obtidos foram submetidos à análise de variância. Nos três experimentos conduzidos no ano agrícola 1995/96, a comparação de médias foi feita pelo teste de Duncan, a 5\% de probabilidade. Os dados do Experimento IV foram submetidos à análise de regressão. Nas equações foram usados os valores $5,7,9$ e 11 correspondendo, respectivamente, às densidades de $50.000,70.000,90.000$ e $110.000 \mathrm{pl} / \mathrm{ha}$.

\section{RESULTADOS E DISCUSSÃO}

Nos quatro experimentos, não se verificaram efeitos significativos da interação genótipos e densidades de plantas relativos às variáveis testadas, ou seja, os níveis de um fator variaram independentemente dos níveis do outro fator.

Nas épocas de semeadura de agosto (Experimento I) e dezembro (Experimento III), a altura da planta e da inserção da espiga de milho foram menores em relação à de outubro (Tabela 1). Nessas duas épocas de semeadura, os híbridos não responderam ao aumento da densidade de 50 para $90.000 \mathrm{pl} / \mathrm{ha}$, em termos de rendimento de grãos. Por outro lado, na semeadura de outubro (Experimento II) obtiveram-se maiores rendimentos de grãos na densidade de $70.000 \mathrm{pl} / \mathrm{ha}$ em relação às densidades de 50.000 e $90.000 \mathrm{pl} /$ ha (Tabela 1).

A ausência de resposta à densidade de plantas nos Experimentos I e III pode ser devida ao menor teto de produtividade verificado nessas épocas de semeadura em relação ao do Experimento II (Tabela 1).

Quanto aos componentes do rendimento, o número de espigas por planta não variou com a densidade de plantas, nos Experimentos I e III. No Expe- 
rimento II, o maior número de espigas por planta foi verificado na densidade de $50.000 \mathrm{pl} /$ ha (Tabela 1 ). O número de grãos por espiga e o peso de mil grãos, de modo geral, diminuíram à medida que se elevou a densidade das plantas de 50.000 para $90.000 \mathrm{pl} / \mathrm{ha}$, nos três experimentos (Tabela 1).

No Experimento IV, os híbridos responderam de forma quadrática ao aumento da densidade das plantas, aumentando o rendimento de grãos com a elevação da densidade de 50.000 para $70.000 \mathrm{pl} / \mathrm{ha}$ e diminuindo nas duas densidades mais altas (Fig. 1). Pela equação da curva na Fig. 1, determinou-se que os máximos rendimentos de grãos seriam obtidos na densidade de $81.000 \mathrm{pl} /$ ha, na média dos quatro híbridos. Esses resultados foram semelhantes aos obtidos no Experimento II, talvez devido ao maior teto de produtividade obtido nos dois experimentos. O número de espigas por planta, o número de grãos por espiga e o peso de mil grãos diminuíram linearmente com a elevação da densidade de 50.000 para $110.000 \mathrm{pl} /$ ha (Figs. 2a, 2b e 2c).

As reduções verificadas nos componentes do rendimento nos quatro experimentos com a elevação da densidade de plantas podem estar associadas ao

TABELA 1. Rendimento de grãos, componentes do rendimento e outras características agronômicas de milho em três densidades de plantas, na média dos híbridos Pioneer 3063, Pioneer 3207 e Cargill 901, em três épocas de semeadura, nos Experimentos I, II e III. EEA/UFRGS. Eldorado do Sul, RS, 1995/96 1 .

\begin{tabular}{|c|c|c|c|c|}
\hline \multirow[t]{2}{*}{ Variáveis } & \multicolumn{3}{|c|}{ Densidade (plantas/ha) } & \multirow[t]{2}{*}{ C.V. $(\%)$} \\
\hline & 50.000 & 70.000 & 90.000 & \\
\hline Experimento I & \multicolumn{3}{|c|}{ Época de semeadura: 21/08/95 } & \\
\hline Rendimento de grãos ( $\mathrm{t} / \mathrm{ha}$ ) & $7,4 \mathrm{~ns}$ & 7,5 & 7,3 & 10,9 \\
\hline $\mathrm{N}^{\mathrm{o}}$ de espigas/planta & $0,99 \mathrm{~ns}$ & 0,99 & 0,97 & 6,5 \\
\hline $\mathrm{N}^{0}$ de grãos/espiga & $428 \mathrm{a}$ & $379 \mathrm{~b}$ & $315 \mathrm{c}$ & 10,5 \\
\hline Peso de mil grãos (g) & $339 a$ & $323 a$ & $291 b$ & 6,2 \\
\hline Plantas estéreis (\%) & $1,76 \mathrm{~ns}$ & 2,34 & 2,57 & 58,0 \\
\hline Índice de colheita & $0,50 \mathrm{~ns}$ & 0,48 & 0,48 & 6,0 \\
\hline Altura de planta (m) & $2,21 \mathrm{~ns}$ & 2,20 & 2,20 & 2,5 \\
\hline Altura de inserção de espiga (m) & $0,83 \mathrm{~ns}$ & 0,84 & 0,85 & 4,0 \\
\hline Experimento II & \multicolumn{3}{|c|}{ Época de semeadura: 10/10/95 } & \\
\hline Rendimento de grãos ( $\mathrm{t} / \mathrm{ha}$ ) & $8,3 \mathrm{~b}$ & $9,1 \mathrm{a}$ & $8,7 \mathrm{ab}$ & 8,1 \\
\hline $\mathrm{N}^{\circ}$ de espigas/planta & $0,98 \mathrm{a}$ & $0,93 b$ & $0,91 \mathrm{~b}$ & 4,9 \\
\hline № de grãos/espiga & $449 \mathrm{a}$ & $410 \mathrm{~b}$ & $361 \mathrm{c}$ & 7,5 \\
\hline Peso de mil grãos (g) & $344 \mathrm{a}$ & $339 b$ & $313 b$ & 4,1 \\
\hline Plantas estéreis $(\%)$ & $3,45 b$ & $6,64 a$ & $8,21 \mathrm{a}$ & 27,1 \\
\hline Índice de colheita & $0,50 \mathrm{~ns}$ & 0,51 & 0,49 & 6,0 \\
\hline Altura de planta $(\mathrm{m})$ & $2,49 \mathrm{~ns}$ & 2,44 & 2,46 & 5,1 \\
\hline Altura de inserção de espiga (m) & $1,13 \mathrm{~ns}$ & 1,12 & 1,14 & 8,9 \\
\hline Experimento III & \multicolumn{3}{|c|}{ Época de semeadura: 12/12/95 } & \\
\hline Rendimento de grãos (t/ha) & $4,8 \mathrm{~ns}$ & 4,4 & 4,4 & 19,5 \\
\hline $\mathrm{N}^{\mathrm{o}}$ de espigas/planta & $0,84 \mathrm{~ns}$ & 0,80 & 0,78 & 16,2 \\
\hline $\mathrm{N}^{\mathrm{o}}$ de grãos/espiga & $433 a$ & $421 \mathrm{a}$ & $320 \mathrm{~b}$ & 10,7 \\
\hline Peso de mil grãos (g) & $278 \mathrm{a}$ & $257 \mathrm{~b}$ & $270 a b$ & 7,6 \\
\hline Plantas estéreis (\%) & $11,9 \mathrm{~ns}$ & 17,9 & 20,0 & 36,8 \\
\hline Índice de colheita & $0,47 \mathrm{~ns}$ & 0,48 & 0,46 & 10,2 \\
\hline Altura de planta $(\mathrm{m})$ & $2,39 \mathrm{~ns}$ & 2,40 & 2,40 & 3,3 \\
\hline Altura de inserção de espiga (m) & $1,21 \mathrm{~ns}$ & 1,18 & 1,18 & 4,5 \\
\hline
\end{tabular}

${ }^{1}$ Médias seguidas pela mesma letra na linha não diferem significativamente entre si pelo teste de Duncan a $5 \%$ de probabilidade; ns: não-significativo. 
aumento da competição entre plantas, em decorrência da menor disponibilidade de radiação solar na comunidade (Tollenaar et al., 1992).

O maior rendimento de grãos obtido na densidade de $70.000 \mathrm{pl} /$ ha nos Experimentos II e IV, mesmo com as reduções nos componentes do rendimento, deve-se, principalmente à pequena redução no número de espigas por planta (Tabela 1 e Fig. 2a) e ao pequeno incremento no percentual de plantas estéreis em relação à densidade de $50.000 \mathrm{pl} / \mathrm{ha}$ (Tabela 1 e Fig. 2d). Segundo Tollenaar et al. (1992), esses pequenos decréscimos no percentual de plantas estéreis podem estar associados ao maior sincronismo entre pendoamento e espigamento. Isto determina adequada fertilização dos óvulos da espiga, visto que o aumento do número de plantas estéreis é atribuído ao atraso da emergência do estilete em relação à liberação do pólen.

Os resultados de rendimento de grãos obtidos nos Experimentos II e IV diferem dos obtidos por Peixoto (1996), que, ao avaliar o efeito de diferentes densidades de plantas em dois níveis de fertilidade do solo e de água sobre os mesmos híbridos testados nesses experimentos, concluiu que houve au-

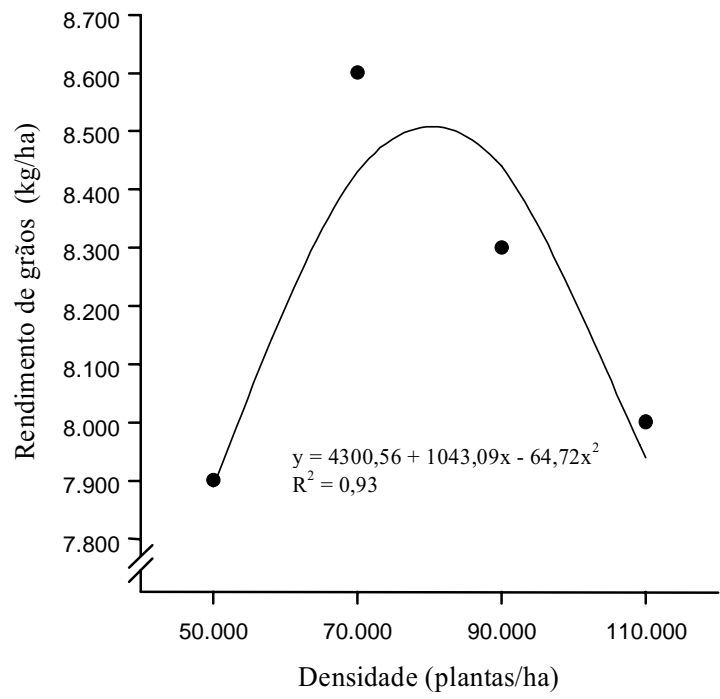

FIG. 1. Rendimento de grãos de milho em quatro densidades de plantas, na média de quatro híbridos (Pioneer 3063, Pioneer 3207, XL 212, Cargill 901) no Experimento IV. EEA/UFRGS. Eldorado do Sul, RS, 1996/97. mento linear no rendimento de grãos à medida que se incrementou a densidade de 30.000 para 90.000 plantas/ha. Porém esta resposta foi mais evidente no experimento com alto nível de manejo (elevado nível de adubação e irrigação suplementar), em que os níveis de produtividade foram mais altos, ao passo que no experimento com médio nível de manejo, com produtividade mais baixa, os rendimentos foram inferiores na densidade de 90.000 plantas/ha em relação à de 70.000 plantas/ha. Essa resposta diferencial entre níveis de manejo indica a possibilidade do emprego de densidades maiores do que 70.000 plantas/ha somente quando for utilizado alto nível de manejo.

Nos quatro experimentos, a estatura da planta e a altura da inserção de espiga não variaram com a densidade de plantas. O índice de colheita que expressa a síntese, translocação, partição e o acúmulo de produtos fotoassimilados não foi afetado pela densidade de plantas nas três épocas de semeadura testadas (Tabela 1).

No Experimento IV, houve efeito significativo da interação simples entre híbridos de milho e densidades de plantas na área foliar e no índice de área foliar. Os híbridos Pioneer 3207 e Cargill 901 diminuíram linearmente a área foliar à medida que se elevou a densidade das plantas de 50 para 110.000 plantas/ha (Fig. 3a). Já os híbridos Pioneer 3063 e XL 212 responderam de forma quadrática aos acréscimos na densidade de plantas. Com relação ao índice de área foliar, os híbridos XL 212 e Cargill 901 aumentaram linearmente com o acréscimo da densidade de 50.000 para 110.000 plantas/ha (Fig. 3b). No entanto, os híbridos Pioneer 3063 e Pioneer 3207 responderam de forma quadrática ao aumento da densidade de plantas, aumentando o índice de área foliar com a elevação da densidade de 50.000 para 90.000 plantas/ha e diminuindo na densidade mais alta.

Os rendimentos de grãos foram, em média, $15 \%$ e $48 \%$ inferiores na semeadura de agosto e dezembro, respectivamente, em relação à de outubro (Tabela 1). Tais resultados podem estar associados a alterações na quantidade de radiação solar disponível em decorrência da semeadura em diferentes épocas dentro da estação de crescimento (Noldin, 1985), visto que todos os experimentos receberam 
suplementação hídrica. Isto pode ter interferido no processo de formação e desenvolvimento de espigas e nos outros componentes do rendimento (Flesch, 1978; Dow et al., 1984; Hashemi \& Herbert, 1992),
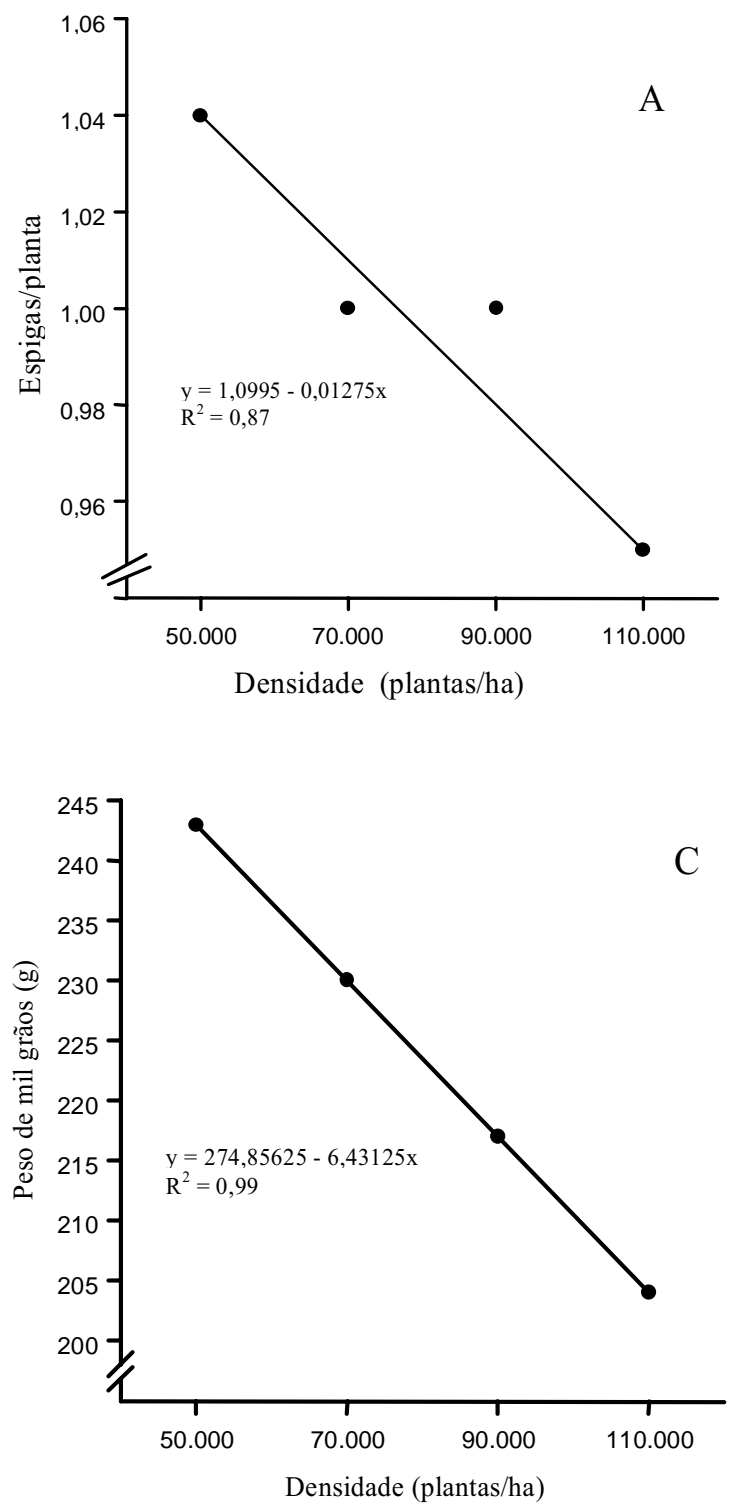

por causa do ajuste entre fonte e demanda. Outro fator que provavelmente influiu para o baixo rendimento de grãos na semeadura de dezembro foi a alta porcentagem de plantas estéreis (Tabela 1).

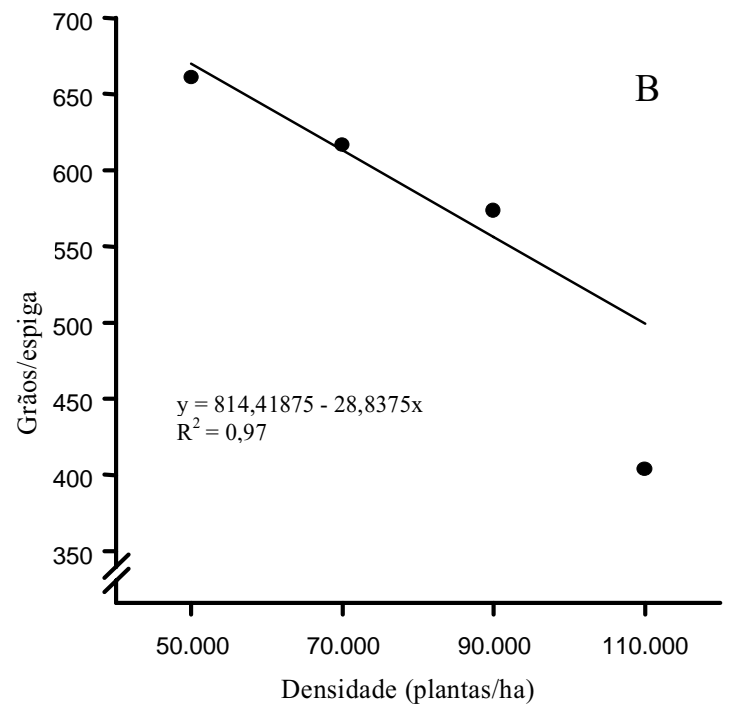

FIG. 2. Número de espigas por planta (A), número de grãos por espiga (B), peso de mil grãos (C) e percentagem de plantas estéreis (D) em milho, em quatro densidades de plantas, na média de quatro híbridos (Pioneer 3063, Pioneer 3207, XL 212 , Cargill 901), no Experimento IV. EEA/UFRGS. Eldorado do Sul, RS, 1996/97. 

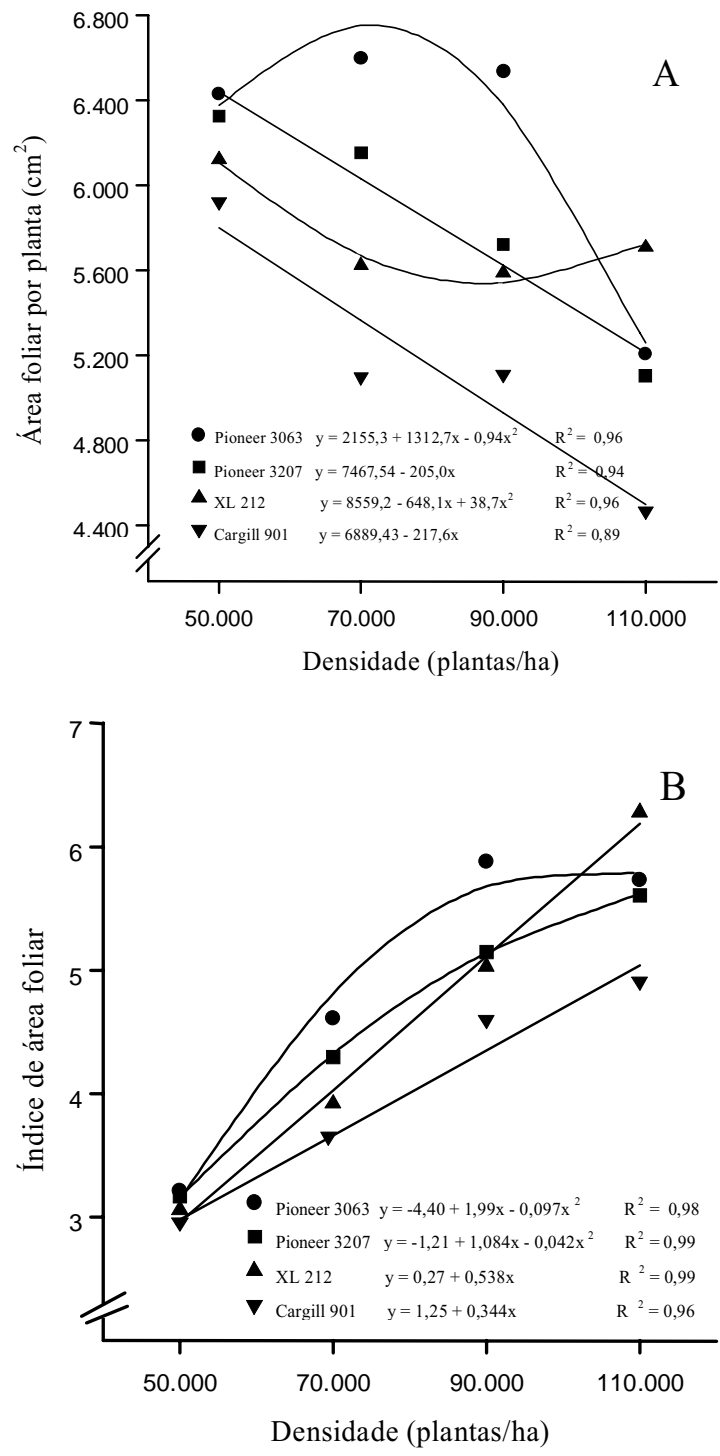

FIG. 3. Área foliar por planta (A) e índice de área foliar de milho (B) em quatro densidades de plantas, na média de quatro híbridos (Pioneer 3063, Pioneer 3207, XL 212, Cargill 901), no Experimento IV. EEA/UFRGS. Eldorado do Sul, RS, 1996/97.

\section{CONCLUSÕES}

1. Não há resposta à densidade de plantas nos três híbridos de milho testados, nas épocas de semeadura de agosto e dezembro.
2. O aumento da densidade de plantas somente foi vantajoso na semeadura de outubro, obtendo-se maiores rendimentos de grãos na densidade de 70.000 plantas/ha, independentemente do híbrido avaliado.

3. Os componentes do rendimento, número de espigas por planta, número de grãos por espiga e peso de mil grãos são afetados negativamente com o aumento da densidade de plantas.

\section{REFERÊNCIAS}

COLVILLE, W.G.; McGILL, D.P. Influence of plant population, hybrid and "productivity level" on irrigated corn production. Agronomy Journal, Madison, v.54, n.3, p.235-238, 1964.

DOW, E.W.; DAYNARD, T.B.; MULDOON, J.F.; MAJOR, D.J.; THURTELL, G.W. Resistance to drought and density in Canadian and European maize (Zea mays L.) hybrids. Canadian Journal of Plant Science, Ottawa, v.64, n.3, p.575-585, 1984.

FLESCH, R.D. Efeitos de duas populações de plantas sobre o desenvolvimento das espigas em três híbridos simples de milho. Porto Alegre:UFRGS, Faculdade de Agronomia, 1978. 98p. Dissertação de Mestrado.

FRANCIS, C.A.; RUTTER, J.N.; PALMER, A.E.E. A rapid method for plant leaf area estimation in maize (Zea mays L.). Crop Science, Madison, v.9, n.5, p.538-539, 1969.

GIRARDIN, P.; TOLLENAAR, M. Effects of intraspecific interference on maize leaf azimuth. Crop Science, Madison, v.34, n.1, p.151-155, 1994.

HASHEMI, D.A.; HERBERT, S.J. Intensifying plant density response of corn with artificial shade. Agronomy Journal, Madison, v.84, n.4, p.547-551, 1992.

MORENO, J.A. Clima do Rio Grande do Sul. Porto Alegre: Secretaria da Agricultura, 1961. 41p.

NOLDIN, J.A. Rendimento de grãos, componentes do rendimento e outras características de planta de três cultivares de milho em duas épocas de semeadura. Porto Alegre: UFRGS, Faculdade de Agronomia, 1985. 149p. Dissertação de Mestrado.

Pesq. agropec. bras., Brasília, v.34, n.4, p.585-592, abr. 1999 
PEIXOTO, C.M. Resposta de genótipos de milho à densidade de plantas, em dois níveis de manejo. Porto Alegre: UFRGS, Faculdade de Agronomia, 1996. 118p. Dissertação de Mestrado.

RUTGER, J.N.; CROWDER, L.V. Effect of high plant density on silage and grain yield of six corn hybrids. Crop Science, Madison, v.7, n.3, p.182-184, 1967.

SILVA, P.R.F. da. Determinação dos efeitos de quatro densidades no rendimento de grãos e características agronômicas, em seis cultivares de milho. Porto Alegre: UFRGS, Faculdade de Agronomia, 1972. 84p. Dissertação de Mestrado.

SOUZA, G.L. de. Influência de densidade de plantas e espaçamento entre linhas sobre o rendimento de grãos, intercepção de luz e outras características agronômicas de duas cultivares de milho (Zea mays L.). Porto Alegre: UFRGS, Faculdade de Agronomia, 1976. 98p. Dissertação de Mestrado.

TETIO-KAGHO, F.; GARDNER, F.P. Responses of maize to plant population density. II. Reproductive development, yield and yield adjustments. Agronomy Journal, Madison, v.80, n.5, p.935-940, 1988.

TOLLENAAR, M.; DWER, L.M.; STEWART, D.W. Ear and kernel formation in maize hybrids respresenting three decades of grain yield improvement in Ontario. Crop Science, Madison, v.32, n.2, p.432-438, 1992. 